might be more challenging. Recent clinical evidence, however, has suggested that recreation of a double coronary artery system by means of reimplantation might allow for normalization of coronary flow reserve $\mathrm{e}^{3}$ and for greater protection against secondary coronary/bypass graft changes because of age and atherosclerosis. ${ }^{2}$ On the basis of these considerations, repair by means of coronary button reimplantation was performed in our patient. Because of the unusual combination of ARCAPA and ACCAPA, translocation of the coronary button proved complex, requiring extensive skeletonization of the proximal RCA and CxA combined with the trapdoor technique, as derived by experience with the arterial switch operation. Evidence of normalization of treadmill test results 3 months after repair confirms that reimplantation should always be attempted, even in adults with isolated ARCAPA or ACCAPA.

\section{References}

1. Radke PW, Messmer BJ, Haager PK, Klues HG. Anomalous origin of the right coronary artery: preoperative and postoperative hemodynamics. Ann Thorac Surg. 1998;66:1444-9.

2. Yao CT, Wang JN, Yeh CN, Huang SC, Yang YR, Wu JM. Isolated anomalous origin of right coronary artery from the main pulmonary artery. J Card Surg. 2005;20:487-9.

3. Veselka J, Widimsky P, Kautzner J. Reimplantation of anomalous right coronary artery arising from the pulmonary trunk leading to normal coronary flow reserve late after surgery. Ann Thorac Surg. 2003;76: 1287-9.

4. Alexi-Meskishvili V, Dahnert I, Hetzer R, Lange PE, Karl TR. Origin of the circumflex coronary artery from the pulmonary artery in infants. Ann Thorac Surg. 1998;66:1406-9.

5. Bolognesi R, Alfieri O, Tsialtas D, Manca C. Surgical treatment of the left circumflex coronary artery from the pulmonary artery in an adult patient. Ann Thorac Surg. 2003;75:1642-3.

\title{
Bronchogenic cyst: Unexpected finding in a large aneurysm of the pars membranacea septi
}

\author{
Frediano Inzani, MD, ${ }^{\text {a }}$ Franco Recusani, MD, ${ }^{\mathrm{b}}$ Manuela Agozzino, MD, ${ }^{\mathrm{a}}$ Alessandra Cavallero, MD, \\ Paolo M. De Siena, MD, ${ }^{c}$ Andrea D'Armini, MD, ${ }^{c}$ Mario Viganò, ${ }^{c}$ and Eloisa Arbustini, MD, ${ }^{\text {a,d }}$ Pavia, Italy
}

I ntracardiac bronchogenic cysts are rare, with only 5 cases reported to date: 2 in the atrial septum, ${ }^{1,2} 1$ in the left atrium, ${ }^{3}$ and 2 in the right ventricle., ${ }^{4,5}$ They are identified by asymptomatic occasional findings or nonspecific symptoms, mostly in the second to fourth decades. ${ }^{3}$

Bronchogenic cysts are believed to represent a localized portion of the tracheobronchial tree that separates from the normal airways during the branching process and does not undergo further development. They develop between the 26th and the 40th day of intrauterine life, during the most active period of airway development. ${ }^{3}$ The timing of the abnormal budding may determine the location: earlier in the mediastinum and later within lung tissue, which are the 2 most common locations. ${ }^{3}$ Intracardiac location can be explained with a more precocious abnormal bud-

From the Pathology Institute, ${ }^{\mathrm{a}}$ Cardiology, ${ }^{\mathrm{b}} \mathrm{C}$ Dubost Transplant Centre, ${ }^{\mathrm{c}}$ and Transplant Research Area, Centre for Inherited Cardiovascular Diseases, ${ }^{\mathrm{d}}$ IRCCS Policlinico San Matteo, University of Pavia, Pavia, Italy.

Supported by research grants "Ricerche Finalizzate e Correnti" IRCCS Policlinico San Matteo of Pavia, Italy.

Received for publication May 31, 2006; accepted for publication June 6, 2006.

Address for reprints: Eloisa Arbustini, MD, Transplant Research Area, IRCCS Policlinico San Matteo, Piazzale Golgi 2, 27100 Pavia, Italy (E-mail: e.arbustini@smatteo.pv.it).

J Thorac Cardiovasc Surg 2006;132:972-4

$0022-5223 / \$ 32.00$

Copyright $\odot 2006$ by The American Association for Thoracic Surgery doi:10.1016/j.jtcvs.2006.06.022 ding, approximately 21 days after fertilization, when the cardiac primordial tube is near the foregut or primitive tracheobronchial tree. $^{2}$

Other noncardiac, atypical locations are cutaneous, retroperitoneal, cervical, intradiaphragmatic, intrapericardial, intraspinal, and intrapleural. $^{2}$

We report a case of a bronchogenic cyst located in the wall of a large aneurysm of the pars membranacea septi triggering premature ventricular complex (PVC) and sinus tachycardia.

\section{Clinical Summary}

A 5-year-old girl was referred to us for the occasional finding of PVC first recorded in 2001 in the third month of life, and confirmed in further controls. Two years later, a Holter monitoring documented sinus tachycardia with several PVCs. An echocardiographic study indicated a possible aneurysm of the left Valsalva sinus. The left atrium and ventricle were moderately enlarged. In 2004, a further echocardiogram described the lesion as a "subaortic aneurysm of the left ventricle."

On November 2005 the girl presented with normal cardiac tones and apparently free pauses; the chest roentgenogram showed a slightly enlarged cardiac shadow. The electrocardiogram confirmed sinus rhythm with respiratory arrhythmia and several PVCs. Transthoracic echocardiography documented an "aneurysm of the pars membranacea septi" with internal diameter of $2 \mathrm{~cm}$ (Figure 1,A). Tricuspid, mitral, aortic, and pulmonary valves showed normal function. The need for an angiocomputed tomography scan was discussed, but it was decided that echocardiography was sufficient for surgery. Indication for surgical excision was based on the potential link between the aneurysm and the PVC, and on the potential risk of emboliza- 

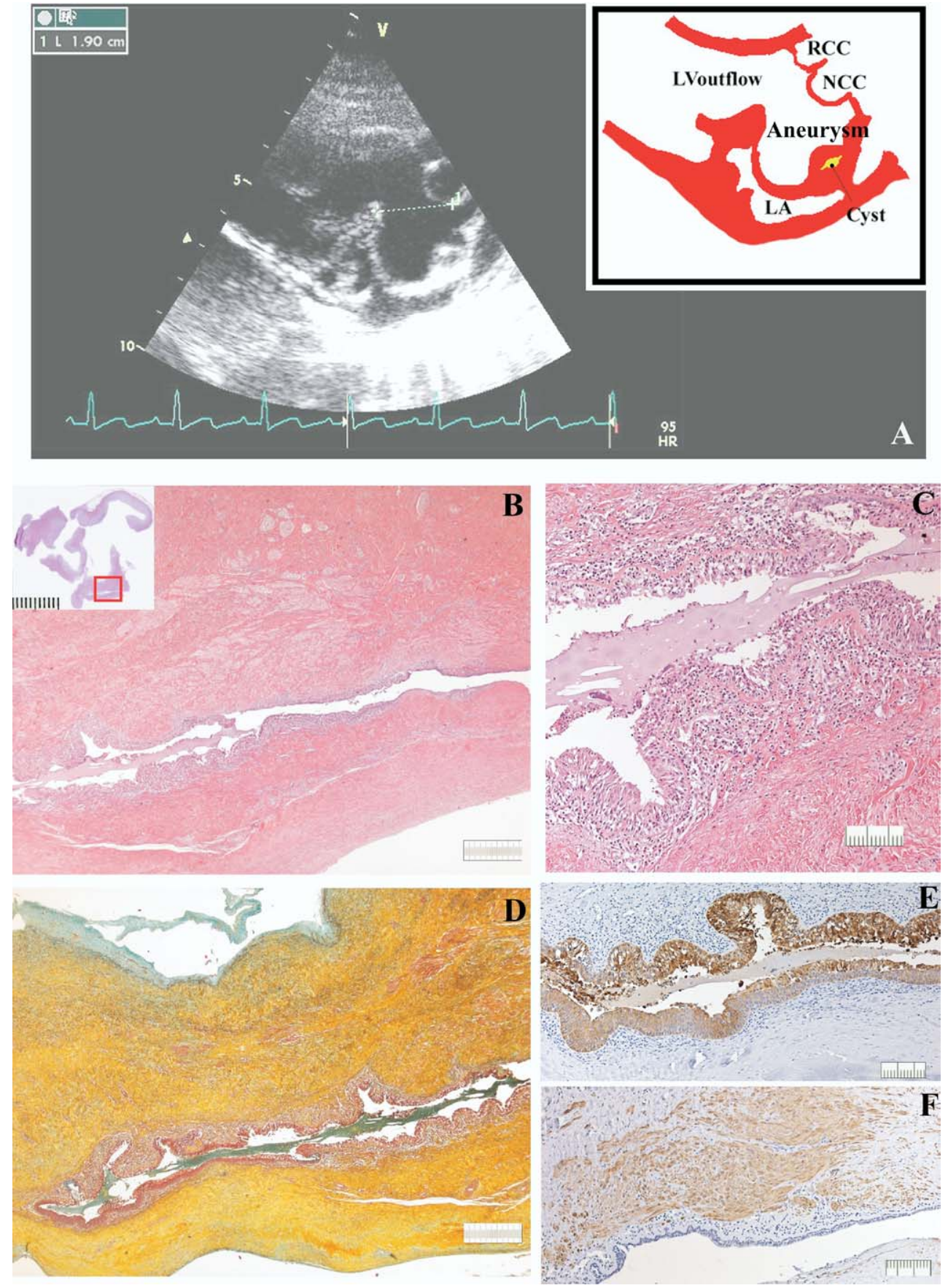

Figure 1. A, Echocardiographic imaging of the aneurysm and cyst; although visible at the echocardiography, the cyst was a non-expected finding at the pathologic study. Inset: aneurysm and cyst (yellow) profiles. B-F, The histopathologic study showed a bronchogenic cyst lined by epithelial cells. The wall of the cyst was composed of irregular groups of smooth muscle cells (B); inset: aneurysm walls with the cyst squared in red. C, The lining was composed of epithelial respiratory type cells, with foci of squamous metaplasia. D, Movat pentachrome stain of (B). Immunohistochemical stains, with anti-cytokeratin 7 antibodies (E) and anti-smooth muscle actin antibodies (F) staining the epithelium and smooth muscle cells, respectively. Bars: $520 \mu \mathrm{m}$ (B, D); square $=1 \mathrm{~cm}$ (B); $135 \mu \mathrm{m}$ (C, E, F). RCC, Right common carotid; NCC, noncoronary cusp; $L A$, left atrium. 
tion. The girl underwent successful surgery and is doing well 1 year after the resection. Sinus tachycardia and PVC were no longer recorded after surgery, suggesting a cause and effect relationship between the aneurysm and the arrhythmias.

The pathologic study showed a mucus-filled bronchogenic cyst of approximately $1 \mathrm{~cm}$ in its greatest diameter. The cyst was located within the wall of the aneurysm. The cyst lining was in part ciliated, columnar of respiratory type, and in part polyptychial cubical, with interposed mucous cells and foci of squamous metaplasia with mild lymphocyte infiltrates. Irregular bundles of smooth muscle cells were present in the thickness of the cyst wall (Figure 1, B, F).

\section{Discussion}

The bronchogenic cyst was a non-expected finding at the pathologic study of the removed aneurysm that constituted the major lesion. This case documents the possible presence of a bronchogenic cyst within the wall of an aneurysm of the pars membranacea septi.

Prior reported cases are different from the present one because the bronchogenic cysts were large enough to be detected as cysts at the echocardiography or computed tomography scan study. ${ }^{1-5} \mathrm{In}$ our patient the lesion diagnosed with echocardiography was the aneurysm. A small cystic space was suspected (Figure 1, A) but did not influence the echocardiography diagnosis and the surgical decision.

A bronchogenic cyst is a benign lesion. Surgical treatment is controversial, ${ }^{2}$ especially in patients without clinical symptoms. However, the benignant nature of the cyst is unknown before pathologic examination. Moreover, the cyst may progressively enlarge ${ }^{1}$ because of mucus accumulation and inflammation of the wall. Analogously to other cardiac masses, it may trigger complications such as arrhythmias, conduction disturbances, obstruction of blood flow, or embolization. ${ }^{2-4}$

\section{References}

1. Soeda T, Matsuda M, Fujioka Y, Doui K, Maruhashi H. A case report of a huge bronchogenic cyst originated in the atrial septum. Nippon Kyobu Geka Gakkai Zasshi. 1996;44:1781-6.

2. Kawase Y, Takahashi M, Takemura H, Tomita S, Watanabe G. Surgical treatment of a bronchogenic cyst in the interatrial septum. Ann Thorac Surg. 2002;74:1695-7.

3. Lee T, Tsai IC, Tsai WL, Jan YJ, Lee CH. Bronchogenic cyst in the left atrium combined with persistent left superior vena cava: the first case in the literature. Am J Roentgenol. 2005;185:116-9.

4. Weinrich M, Lausberg HF, Pahl S, Schafers HJ. A bronchogenic cyst of the right ventricular endocardium. Ann Thorac Surg. 2005;79:e13-4.

5. Prates PR, Lovato L, Homsi-Neto A, Barra M, Sant'Anna JR, Kalil RA, et al. Right ventricular bronchogenic cyst. Tex Heart Inst J. 2003;30: 71-3.

\section{Coronary artery bypass grafting and biventricular pacing efficacy: Do past trials dictate a change in future practice?}

Omid Hajiseyedjavadi, MD, MSc, Michael Pasque, MD, Marc Moon, MD, Ralph Damiano, MD, Teodoro Mucha, BS, Keith Hebert, BS, and Nader Moazami, MD, St Louis, Mo

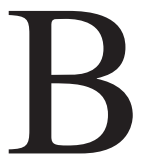
iventricular pacing, or chronic resynchronization therapy (CRT), has been increasingly used in management of patients with class III to IV heart failure who have evidence of interventricular conduction delay. Despite the widespread use of this therapy, the endocardial procedure required for left ventricular (LV) lead placement can be labor

From Washington University, Barnes Hospital, St Louis, Mo.

Medtronic is the sponsor of the MIRACLE trial, which provided the data for this study. R.D. reports consulting and lecture fees from Medtronic. T.M. and K.H. report that they are employees of Medtronic and hold stock options in the company.

Received for publication Aug 27, 2005; accepted for publication April 14, 2006.

Address for reprints: Omid Hajiseyedjavadi, MD, MSc, 12513 E Lupine Ave, Scottsdale, AZ 85259 (E-mail: javadio@wustl.edu).

J Thorac Cardiovasc Surg 2006;132:974-5

$0022-5223 / \$ 32.00$

Copyright $\odot 2006$ by The American Association for Thoracic Surgery doi:10.1016/j.jtcvs.2006.04.049 intensive and fails in approximately $10 \%$ of patients. ${ }^{1,2}$ In fact, the LV lead placement in the Multicenter InSync Randomized Clinical Evaluation (MIRACLE) trial was associated with the highest rate of complication. ${ }^{1}$ Large number of patients undergoing cardiac surgery have some degree of systolic dysfunction in conjunction with interventricular conduction delay. Prophylactic epicardial LV lead placement in this setting may be beneficial and can be performed with ease. In the absence of any trials showing the beneficial effects of prophylactic LV lead placement during cardiac surgery, we sought to perform a subgroup analysis of the Multicenter InSync Implantable Cardioverter-Defibrillator (ICD) Randomized Clinical Evaluation (MIRACLE-ICD) trial to determine whether the beneficial effects of biventricular pacing continue to be evident in patients who had previously undergone coronary artery bypass grafting (CABG).

\section{Methods}

A review of the raw data from the MIRACLE-ICD trial was performed to determine the response to CRT of patients with coronary artery disease who received biventricular therapy long 